\title{
PERANCANGAN APLIKASI PEMBELAJARAN SUKU BANYAK BERBASIS MULTIMEDIA
}

\author{
J. Jamaluddin \\ Dosen D-III Manajemen Informatika - Universitas Methodist Indonesia \\ Email:jac.satuno@gmail.com
}

\begin{abstract}
ABSTRAK
Seiring dengan meningkatnya jumlah kepemilikan perangkat personal komputer oleh berbagai pihak, maka kebutuhan akan tersedianya aplikasi pembelajaran berbantuan komputer pun semakin meningkat dan perlu mendapat perhatian serius. Agar diperoleh efektivitas yang tinggi, maka pengembangan program pembelajaran berbantuan komputer perlu direncanakan dengan baik, yakni dengan memperhatikan aspekaspek: umpan balik, percabangan, penilaian, monitoring kemajuan, petunjuk, dan tampilan. Penelitian ini diimplementas-kan menggunakan bahasa pemrograman ActionScript dengan perangkat lunak Adobe Flash. Sehingga dihasilkan sebuah Aplikasi Pembelajaran Berbantuan Komputer Suku Banyak yang mudah dioperasikan dan interaktif.
\end{abstract}

Keywords: Pembelajaran, Multimedia, Suku Banyak.

\section{PENDAHULUAN}

Seiring dengan perkembangan teknologi dewasa ini, sebagian besar sekolah-sekolah yang ada di Indonesia khususnya di daerah perkotaan telah banyak yang memanfaatkan media komputer sebagai alat bantu dalam proses belajar mengajar.

Pembelajaran Berbantuan Komputer atau Computer Aided Instruction yang biasa disingkat dengan CAI merupakan suatu sistem pembelajaran dan pengajaran yang mendayagunakan perangkat komputer sebagai alat bantu dalam proses belajar mengajar. Aplikasi pembelajaran adalah pengembangan dari teknologi informasi terpadu yang saling mendukung yakni pencitraan, audio, video dan komunikasi (interaktif) yang dikemas dengan sebutan teknologi multimedia. Sedangkan multimedia dapat didefinisikan sebagai kombinasi dari teks, foto, seni grafis, suara, animasi, dan elemen-elemen video yang dimanipulasi secara digital ${ }^{[5]}$.

Pendayagunaan perangkat komputer dalam menunjang proses belajar mengajar baik itu oleh guru maupun siswa secara personal sangat diperlukan didalam menujang pemahaman para siswa untuk memahami teori yang dipaparkan. Karena hal tersebutlah, maka penulis mendapatkan ide untuk merancang aplikasi pembelajaran berbasis multimedia yang dapat diaplikasikan untuk membangun aplikasi pebelajaran pada setiap mata pelajaran.

\section{TINJAUAN PUSTAKA MULTIMEDIA}

Multimedia adalah kombinasi dari teks, gambar, seni grafik, suara, animasi dan elemen-elemen video yang dimanipulasi secara digital ${ }^{[5]}$. Meskipun definisi multimedia sangat sederhana, tetapi cara untuk menjalankannya sangatlah kompleks. Tidak hanya memahami bagaimana setiap elemen multimedia dibuat dan dapat bergerak, tetapi bagaimana cara menggunakan piranti dan teknologi komputer multimedia untuk dapat menggabungkan semua elemen bersama-sama.

Piranti perangkat lunak, pesan-pesan dan isi yang ditampilakan dalam layer komputer atau televisi bersama-sama membentuk sebuah proyek multimedia. Menentukan bagaimana seorang pengguna akan berinteraksi dan menelusuri isi dari suatu proyek multimedia membutuhkan perhatian yang besar pada pesan, storyboarding, karya seni, dan pemrograman.

Penerapan multimedia telah mencakup berbagai aspek kehidupan bermasyarakat, diantaranya:

a. Multimedia dalam Pendidikan

Sekolah mungkin merupakan instuisi yang paling membutuhkan multimedia. Pemanfaatan multimedia yang menarik di sekolah-sekolah melibatkan para siswa itu sendiri. Siswa dapat menikmati sistem belajar yang interaktif.

b. Multimedia dalam Bisnis

Aplikasi bisnis untuk multimedia meliputi presentasi, pelatihan, pemasaran, periklanan, demo produk, database, katalog, pesan kilat dan komunikasi jaringan.

c. Multimedia di Tempat Umum 
Di hotel, stasiun kereta api, mal perbelanjaan, museum dan terminal.

\section{ANALISIS DAN PERANCANGAN}

Perancangan pada aplikasi pembelajaran ini tiga tahapan perancangan yaitu Perancangan dengan Data Flow Diagram (DFD), Perancangan dengan menggunakan FlowChart sebagai diagram alir aplikasi dan perancangan tampilan aplikasi.

DFD terdiri dari diagram konteks dan diagram rinci. Diagram Konteks berfungsi memetakan model lingkungan (menggambarkan hubungan antara entitas luar, masukkan dan keluaran sistem), yang direpresentasikan dengan lingkaran tunggal yang mewakili keseluruhan sistem. Pada aplikasi pembelajaran suku banyak, diagram konteks dapat dilihat pada Gambar 1 berikut:

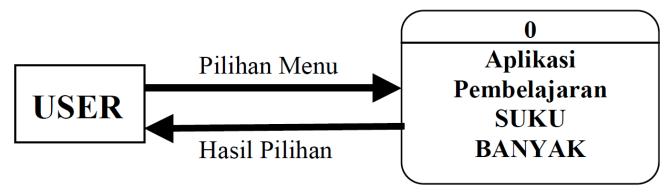

Gambar 1. Diagram Konteks Aplikasi Pembelajaran Suku Banyak

FlowChart (Bagan Alir Program) adalah suatu bagan yang menggambarkan arus logika dari data yang akan diproses dalam suatu program dari awal sampai akhir. FlowChart berguna bagi pemrogram (programmer) aplikasi untuk mempersiapkan program yang rumit. Pada Gambar 2 ditampilkan FlowChart untuk aplikasi pembelajaran suku banyak.

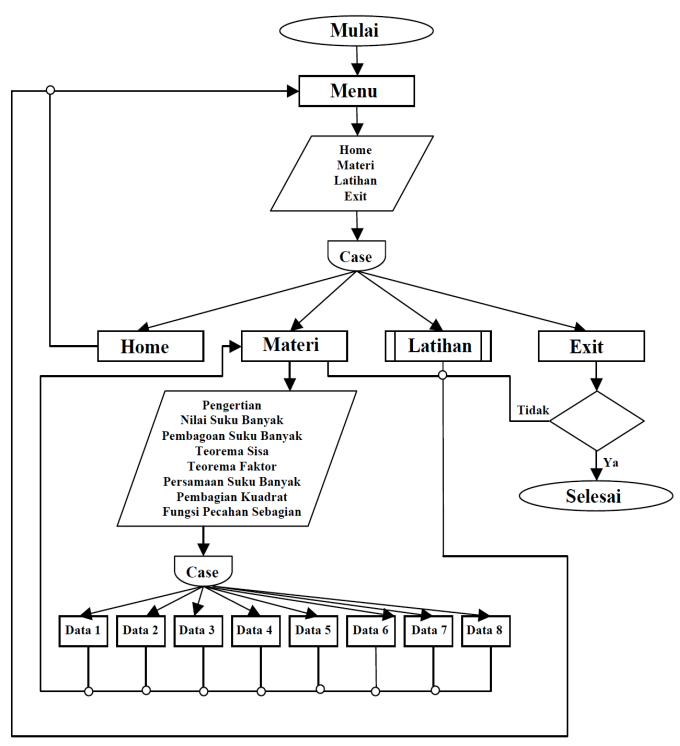

Gambar 2. FlowChart Aplikasi Pembelajaran Suku Banyak

Sedangkan Flowchart pada menu latihan ditampilkan pada Gambar 3 berikut:

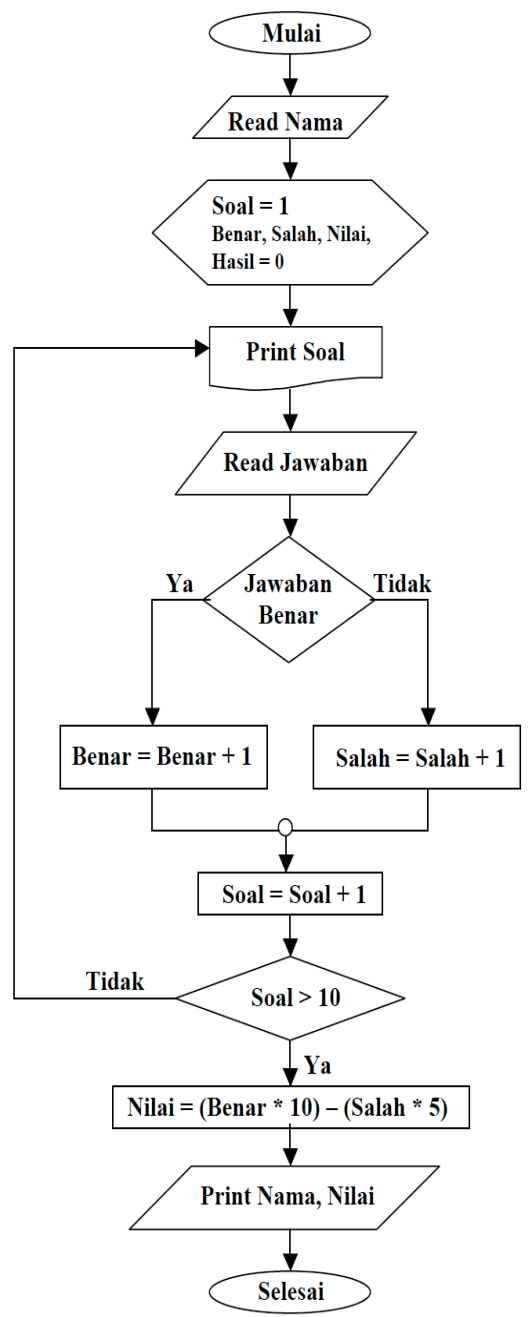

Gambar 3. Flowchart pada Menu Latihan

Perancangan tampilan (interface) aplikasi pembelajaran suku banyak dirancang dengan menggunakan sebuah tampilan utama yang terdiri atas empat menu yakni menu home, menu materi, menu latihan dan exit. Tampilan utama dirancang sedemikian rupa untuk mempermudah user dalam berinteraksi dengan aplikasi. Tampilan utama dirancang dengan fitur-fitur yang menarik dan memudahkan penguna dalam pengoperasiannya (user friendly). Tampilan utama dibagi dalam empat bagian utama yakni bagian atas yang merupakan judul aplikasi, bagian tengan sebelah kiri yang berisikan tombol-tombol navigasi menu, bagian tengah sebelah kanan dibuat kosong 
untuk memunculkan isi dari setiap menu yang ada di sebelah kirinya, dan bagian bawah menampilkan nama pembuat aplikasi. Rancangan untuk tampilan utama aplikasi dapat dilihat pada Gambar 4 berikut:

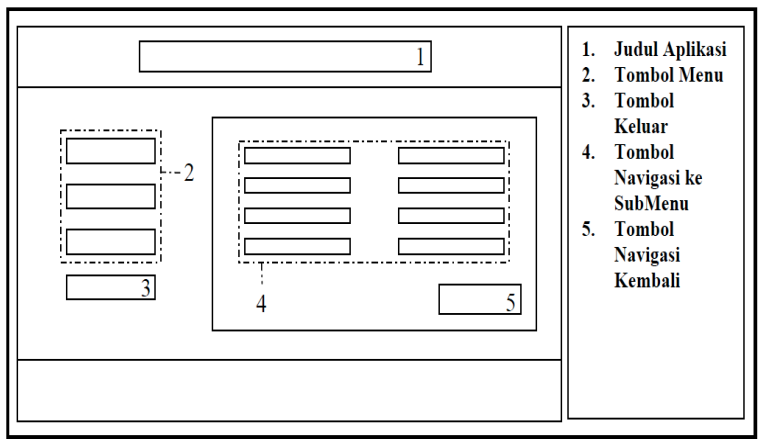

Gambar 4. Rancangan Tampilan Utama Aplikasi

Tampilan menu materi juga dirancang tidak jauh berbeda dengan tampilan utama dan menu home. Pada menu materi bagian isi diletakkan tombol-tombol sebagai navigasi ke submenu materi. Rancangan untuk tampilan menu materi dapat dilihat pada Gambar 5 berikut:

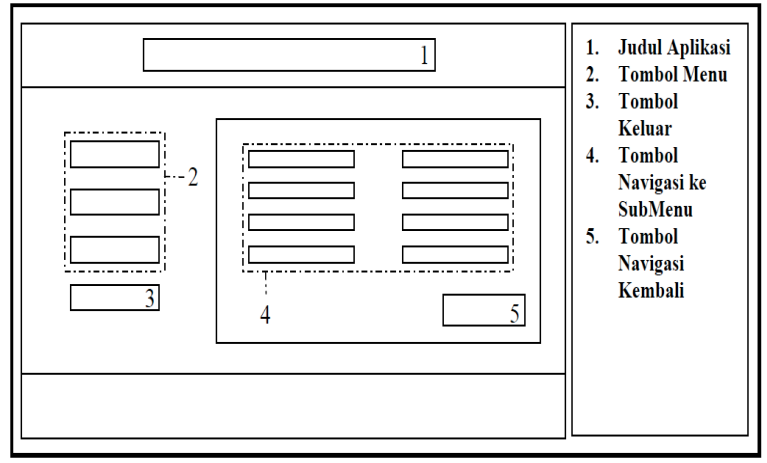

Gambar 5. Rancangan Tampilan Menu Materi

Rancangan untuk tampilan penyampaian materi dapat dilihat pada Gambar 6 berikut:

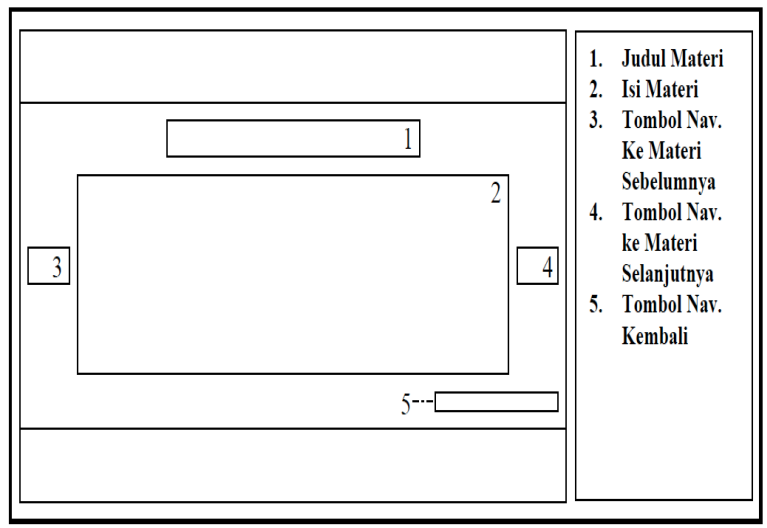

\section{Gambar 6. Rancangan Tampilan Penyampaian Materi}

Tampilan menu latihan dirancang tidak jauh berbeda dengan tampilan-tampilan yang lain. Tampilan menu latihan dibedakan menjadi empat bagian yakni bagian pertama yang berisikan pertanyaan kepada pengguna tentang keyakinan pengguna untuk memulai latihan, bagian kedua yang meminta pengguna untuk mengisikan nama sebelum memulai latihan, bagian ketiga yang beisikan soal-soal latihan dan bagian terakhir yang menampilkan nilai hasil dari latihan. Rancangan tampilan untuk ke empat bagian menu latihan dapat dilihat pada Gambar 7 berikut:

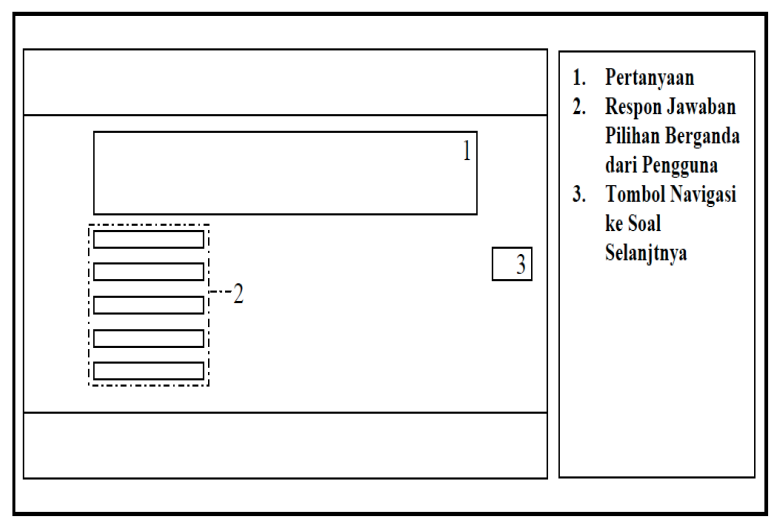

Gambar 7. Rancangan Tampilan Pertanyaan pada Menu Latihan

\section{HASIL DAN PEMBAHASAN}

Aplikasi pembelajaran Suku Banyak ini dibangun dengan menggunakan perangkat lunak Adobe Flash CS dengan menggunakan bahasa ActionScript versi 2.0. Adapun tampilan hasil menu utama dari aplikasi pembelajaran suku banyak dapat dilihat pada Gambar 8 berikut:

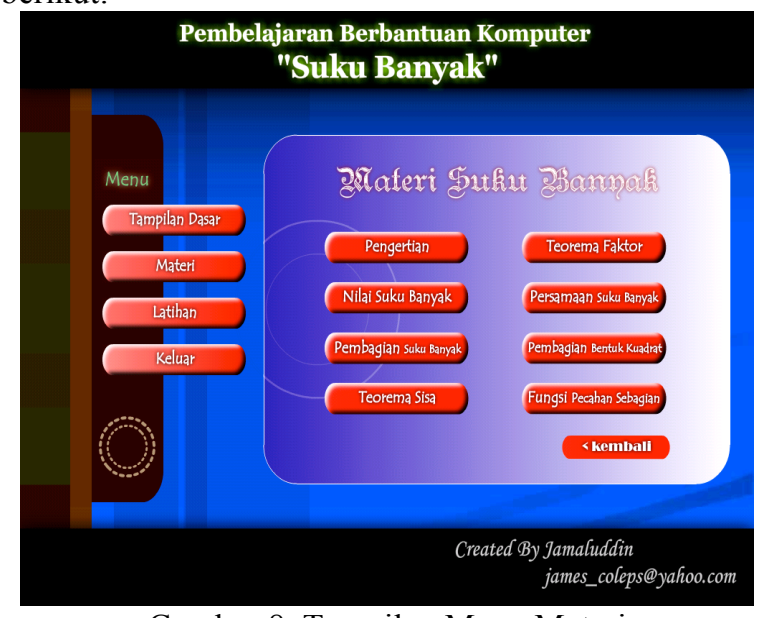

Gambar 8. Tampilan Menu Materi 
Tampilan menu materi terdiri atas delapan submenu materi, yang terdiri dari submenu Pengertian, Nilai Suku Banyak, Pembagian Suku Banyak, Teorema Sisa, Teorema Faktor, Persamaan Suku Banyak, Pembagian Bentuk Kuadrat dan Fungsi Pecahan Sebagian. Pada kanan bawah tampilan juga terdapat menu kembali yang berfungsi untuk kembali ke tampilan utama.

Tampilan submenu materi yang berisikan tentang penjelasan pelajaran suku banyak memiliki tampilan yang lebih sederhana, hal ini bertujuan agar pengguna dalam hal ini siswa dapat lebih berkonsentrasi dalam mempelajari materi yang ditampilkan. Pada tampilan terdapat tombol navigasi panah di sebelah kanan tampilan yang berfungsi untuk melanjutkan ke penjelasan pelajaran berikutnya. Terdapat juga tombol navigasi kembali untuk kembali ke menu materi. Bila Kita mengklik tombol navigasi panah yang ada disebelah kanan tampilan maka akan muncul tampilan seperti yang terlihat pada Gambar 9 berikut:

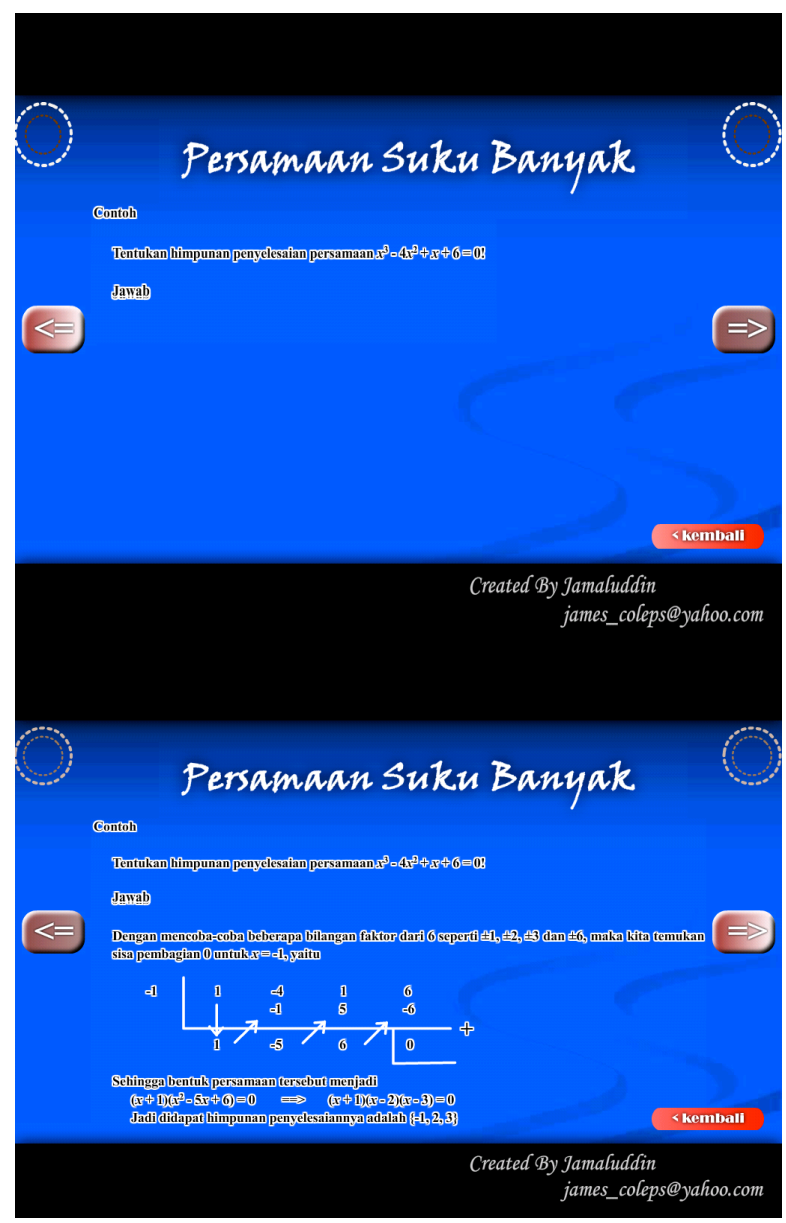

Gambar 9. Tampilan Contoh Latihan (a) dan Proses Pengerjaannya (b) pada Menu Materi

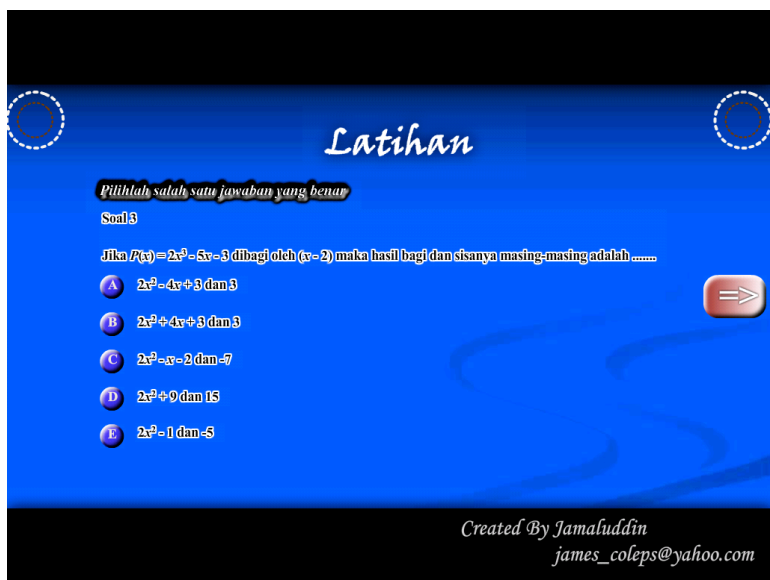

Gambar 10. Tampilan Latihan pada Aplikasi

Pada setiap soal-soal latihan hanya terdapat dua tombol utama yaitu tombol navigasi panah yang terdapat pada sebelah kanan tampilan dan tomboltombol jawaban dari soal yang berjumlah lima buah. Apabila Kita mengklik salah satu jawaban dari soal tersebut maka nilai Benar atau Salah Kita akan bertambah satu, dan akan muncul soal berikunya. Apabila kita tidak yakin akan jawabannya kita hanya perlu mengklik tombol navigasi panah kanan untuk melanjutkan ke soal berikutnya.

\section{KESIMPULAN}

Berdasarkan pembahasan dan evaluasi dari bab-bab terdahulu, maka dapat ditarik kesimpulan sebagai berikut :

1. Aplikasi Pembelajaran Berbantuan Komputer Suku Banyak dirancang dengan tiga tahapan perancangan yaitu dengan Data Flow Diagram (DFD), FlowChart, dan perancangan untuk tampilan aplikasi.

2. Aplikasi Pembelajaran Berbantuan Komputer Suku Banyak dirancang dengan sistem navigasi yang konsisten dan sistem pewarnaan yang nyaman.

3. Penyampaian materi menggunakan prinsip tutorial linier yakni menyajikan suatu topik ke topik berikutnya sesuai urutan yang telah ditetapkan oleh pemrogram.

\section{REFERENSI}

[1] Budianto, I., 2010. Multimedia Digital - Dasar Teori dan Pengembangannya. Yogyakarta: Penerbit ANDI.

[2] Ladjamudin, A.B., 2006. Rekayasa Perangkat Lunak. Yogyakarta: Graha Ilmu.

[3] Sukiman. 2012. Pengembangan Media Pembelajaran Pedagogia. Yogyakarta: Penerbit ANDI. 
[4] Untoro, T.W., Asmara, R. \& Setiawardhana. 2012. Aplikasi Ensiklopedia tentang Alam Semesta Berbasis Multimedia. http://www.pens.ac.id/

[5] Vaughan, T., 2010. Multimedia: Making It Work. $8^{\text {th }}$ Edition. New York: McGrawHill.

[6] Binanto, I., 2010. Multimedia Digital: Dasar Teori + Pengembangannya. Yogyakarta: Penerbit ANDI.

[7] Madcoms, 2008. Panduan Lengkap Adobe Flash CS3 Profesional. Yogyakarta: Penerbit ANDI.

[8] Susanto, J. 2012. Multimedia untuk Media Pembelajaran. http://www.ilmukomputer.org/ 